\title{
Application of atomic absorption spectrometry with continuous light source to analyze selected metals important for human health in different parts of oranges
}

\author{
Wojciech Szwerc, Ireneusz Sowa*, Ryszard Kocjan \\ Department of Analytical Chemistry, Medicinal University in Lublin, Chodzki 4a, 20-093 Lublin, Poland
}

\begin{tabular}{l}
\hline ARTICLE INFO \\
\hline Received 20 August 2014 \\
Accepted 26 August 2014
\end{tabular}

\section{Keywords:}

H-R CS AAS,

metal ions,

elements,

trace analysis,

oranges.

\begin{abstract}
The publication describes the application of high-resolution continuum source atomic absorption spectrometry (H-R CS AAS) to determine some physiologically essential and toxic elements occurring in citrus fruits of different origins. Before analysis, the samples were mineralized using a mixture of deionized water and $69 \%$ nitric acid 3:1 (v/v) in high pressure microwave digestion at $188^{\circ} \mathrm{C}$ during one hour.

The obtained validation parameters for AAS such as high linearity (the correlation coefficient $\mathrm{R}>0.997$ ) and high precision expressed as relative standard deviation (\%RSD) were satisfactory for quantification.

Cadmium at concentration range from 0.29 to $0.43 \mathrm{mg} / \mathrm{kg}$ was determined in all tested samples, however the obtained values did not exceed Polish standards. The higher concentration of potassium comparing to sodium and calcium was noted in each investigated samples. The highest variation was observed for calcium, its concentration strongly depended on the country of origin.
\end{abstract}

\section{INTRODUCTION}

Nowadays, due to substantial progress of analytical techniques, it is possible to determine trace amount of analytes. The reduction of detection limits is particularly important for biological samples, e.g. for quantification of physiological and toxic elements. Atomic absorption spectrometry (AAS), atomic emission spectrometry (AES), e.g. flame photometry and anode inversion voltammetry (ASV) are especially recommended for trace analysis of metal ions in the samples of different origin [6].

Flame photometry, due to the simplicity of the apparatus and low operating costs is used as a diagnostic method in hospital laboratories for analysis of physiologically important elements e.g. potassium, magnesium, sodium, calcium at $\mathrm{mg} / \mathrm{L}$ level $[3,9]$. Anode inversion voltammetry technique (ASV) enables the determination at $\mathrm{ng} / \mathrm{L}$ level and can be useful for analyzing samples of human origin such as blood [5]; however, its sensitivity strongly depends on matrix. AAS is the most versatile technique with low limits of detection (LOD) and quantification (LOQ) comparable

Corresponding author

e-mail: i.sowa@umlub.pl to voltammetry. Previously, hollow cathode lamps (HCL) and electrodeless discharge lamps (EDL) were employed as a source of radiation in atomic absorption spectrometers; however, single lamp was dedicated only to one element. Thus, numerous lamps were necessary to analysis of wide range of elements. Nowadays, the latest apparatus have a xenon lamp, which provides continuous light source. It gives the possibility of sequential multielements analysis [4,7].

The aim of our study was application of high-resolution continuum source atomic absorption spectrometry (H-R CS AAS) to determine some physiologically essential and toxic elements occurring in citrus fruits.

\section{MATERIALS AND METHODS}

Chemicals. Calcium, sodium, potassium and cadmium standard solutions at concentration levels of $1000 \mathrm{ppm}$ were supplied from Merck (Darmstadt, Germany). Water was deionized by Ultrapure Millipore Direct-Q-R 3UV (Merck). The resistivity was $18.2 \mathrm{M} \Omega \cdot \mathrm{cm}$ and it was additionally checked conductometrically by Elmetron CX-401 (Elmetron, Poland). Nitric acid 65\% pure for analysis (POCH, Poland) and nitric acid 69\% suprapure (Roth, Germany) were used 
for investigation. The flame was fed with a mixture of gases: air and acetylene. The investigated material constituted peel, pulp and exocarpium of oranges from Spain and Morocco, purchased on the local market.

Standard and sample preparation. Working standard solutions of calcium, sodium, potassium and cadmium were prepared by dilution of stock solutions at a concentration level of $1000 \mathrm{ppm}$ in deionized water. The investigated material was divided on peel, pulp and exocarpium. All parts were shredded, dried at $60^{\circ} \mathrm{C}$ and accurately weighed $(0.5$ g). Samples were digested in a mixture of deionized water and $69 \%$ nitric acid 3:1 in twelve-positions high pressure microwave digestion NovaWave (SCP Science, Canada). Mineralization temperature was set at $188^{\circ} \mathrm{C}$ during one hour. After digestion, the mineralizates were quantitatively transferred to Egertz's tubes and filled with deionized water to a volume of $25 \mathrm{~mL}$.

Atomic Absorption Spectrometer analysis. Contents of calcium, potassium, cadmium and sodium were determined by flame technique of atomic absorption spectrometry using High- Resolution Continuum Source Atomic Absorption Spectrometer ContrAA 700 (Analytik Jena, Germany). The measurements were performed at $\lambda=588.9953 \mathrm{~nm}$ for sodium, $\lambda=422.6728 \mathrm{~nm}$ for calcium, $\lambda=766.4908 \mathrm{~nm}$ for potassium and $\lambda=228.8018 \mathrm{~nm}$ for cadmium.

\section{RESULTS AND DISCUSSION}

The mineralization conditions for plant material were optimized experimentally. The various temperatures, time of digestion as well as the ratio of water to nitric acid were tested. The best efficiency of mineralization was obtained for parameters given in experimental section.

AAS analysis was conducted with the use of flame technique, the automatic simultaneous background correction was done by $\mathrm{CCD}$ detector with the use of references pixels [4]. The calibration curves were constructed based on absorbance signals for different concentrations of standard solutions (Fig.1 - Fig.4). The obtained validation

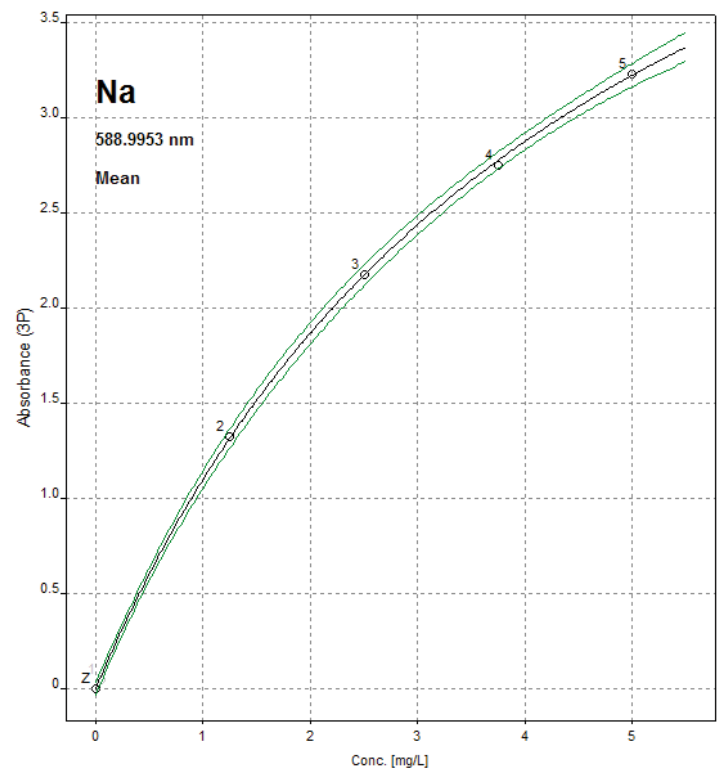

Figure 1. The calibration curve for sodium

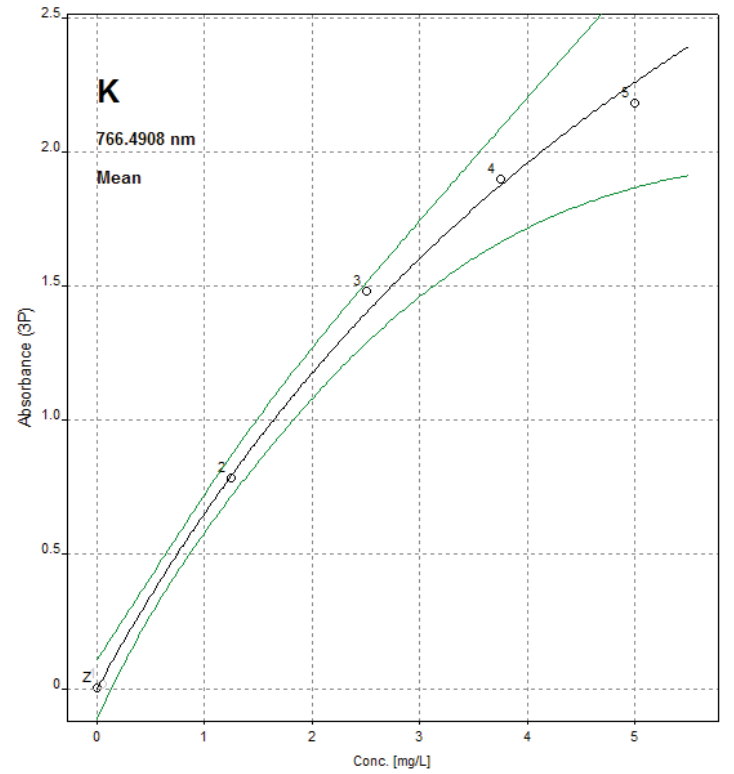

Figure 2. The calibration curve for potassium

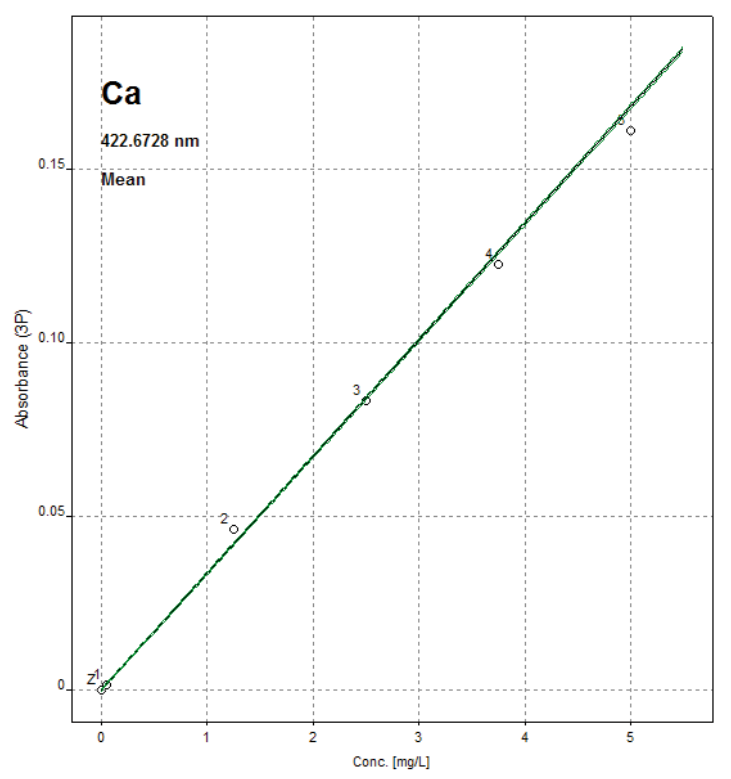

Figure 3. The calibration curve for calcium

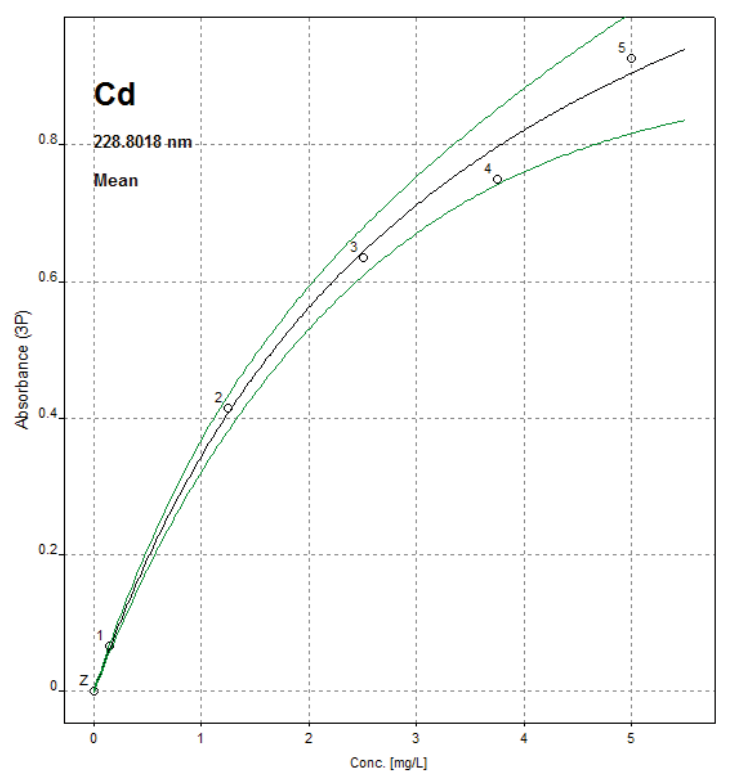

Figure 4. The calibration curve for cadmium

Current Issues in Pharmacy and Medical Sciences 
Table 1. The validation parameters for AAS analysis

\begin{tabular}{|c|c|c|c|c|c|c|c|}
\hline Element & $\begin{array}{l}\text { Concentration } \\
\text { range }(\mathrm{mg} / \mathrm{L})\end{array}$ & $\begin{array}{c}\text { Correlation } \\
\text { coefficient } \\
(\mathrm{R})\end{array}$ & Equation & $\begin{array}{l}\text { Precision } \\
(\% \text { RSD })\end{array}$ & \begin{tabular}{|c|} 
Characteristic \\
concentration $(\mathrm{mg} / \mathrm{L})$ for \\
$1 \%$ of absorbance \\
\end{tabular} & $\begin{array}{l}\text { Burner } \\
\text { height } \\
(\mathrm{mm})\end{array}$ & $\begin{array}{c}\begin{array}{c}\text { Flow of } \\
\text { carrier gases } \\
(\mathrm{L} / \mathrm{h})\end{array} \\
\end{array}$ \\
\hline $\mathrm{Na}$ & \multirow{4}{*}{$0-5$} & 0.99989 & $y=(0.0002064+1.3338693 x) /(1+0.2134803 x)$ & $0.2-5.8$ & 0.0033 & 6 & 90 \\
\hline K & & 0.99771 & $y=(0.0023627+0.7367752 x) /(1+0.1259567 x)$ & $0.1-6.3$ & 0.0059 & 8 & 80 \\
\hline $\mathrm{Ca}$ & & 0.99999 & $y=0.0001960+0.0336162 x$ & $2.8-4.6$ & 0.1297 & 6 & 80 \\
\hline $\mathrm{Cd}$ & & 0.99998 & $y=(0.0006305+0.4440305 x) /(1+0.2907187 x)$ & $1.1-2.2$ & 0.098 & 6 & 50 \\
\hline
\end{tabular}

parameters, e.g. high linearity and precision were satisfactory for quantification. They are summarized in Table 1. Three physiologically essential (K, Na and $\mathrm{Ca}$ ) and one toxic $(\mathrm{Cd})$ elements were investigated in different parts of oranges derived from Spain and Morocco. The amounts of elements in investigated fruits were calculated based on calibration curves. The results are presented in Table 2 and Table 3 . The small amount of cadmium from 0.29 to $0.43 \mathrm{mg} / \mathrm{kg}$ was determined in samples from both countries; however, these values did not exceed Polish standards. The amount of potassium was significantly higher than sodium in investigated samples. The significant differences of sodium, potassium and calcium between different parts of fruits as well as between samples of different origin were observed. The concentration of calcium in oranges from Morocco was much higher than in Spanish fruits.

Table 2. The average content of elements in oranges from Spain $(\mathrm{mg} / \mathrm{kg}] \pm \mathrm{SD})$

\begin{tabular}{|c|c|c|c|}
\hline Elements & Peel & Pulp & Exocarpium \\
\hline $\mathrm{Na}$ & $92.68 \pm 5.09$ & $78.70 \pm 4.32$ & $79.30 \pm 4.36$ \\
\hline $\mathrm{K}$ & $1820.5 \pm 76.46$ & $1567.86 \pm 65.85$ & $684.15 \pm 28.73$ \\
\hline $\mathrm{Ca}$ & $98.49 \pm 3.64$ & $87.92 \pm 3.25$ & $149.93 \pm 5.54$ \\
\hline $\mathrm{Cd}$ & $0.29 \pm 0.006$ & $0.43 \pm 0.007$ & $0.30 \pm 0.005$ \\
\hline
\end{tabular}

Table 3. The average content of elements in oranges from Morocco $(\mathrm{mg} / \mathrm{kg}] \pm \mathrm{SD})$

\begin{tabular}{|c|c|c|c|}
\hline Elements & Peel & Pulp & Exocarpium \\
\hline $\mathrm{Na}$ & $87.84 \pm 4.83$ & $77.66 \pm 4.27$ & $127.85 \pm 7.03$ \\
\hline $\mathrm{K}$ & $1333.36 \pm 56.01$ & $1370.09 \pm 57.54$ & $982.21 \pm 41.25$ \\
\hline $\mathrm{Ca}$ & $236.24 \pm 8.74$ & $955.24 \pm 35.34$ & $107.15 \pm 3.96$ \\
\hline $\mathrm{Cd}$ & $0.37 \pm 0.006$ & $0.36 \pm 0.005$ & $0.37 \pm 0.006$ \\
\hline
\end{tabular}

As our results showed, oranges can be used as a natural source of potassium supplementation because $1 \mathrm{~kg}$ of fruits provides approximately $40-75 \%$ of daily demand. However, the content of sodium is too low and it amounted to c.a. $3 \%$ of daily demand. The calcium concentration strongly depended on the country of origin. One $\mathrm{kg}$ of fruits provided approximately $9 \%$ and $96 \%$ of daily demand for oranges from Spain and Morocco, respectively. The significant differences between the amount of investigated elements can be caused the various environmental conditions e.g. components of soil or water and the other.

\section{CONCUSSION}

The high-resolution continuum source atomic absorption spectrometry (H-R CS AAS) was successfully used to determine the toxic (cadmium) and physiologically essential (calcium, sodium and potassium) elements occurring in different parts of orange from Morocco and Spain. The obtained validation parameters were satisfactory for quantitative analysis of investigated elements. Cadmium (from 0.29 to $0.43 \mathrm{mg} / \mathrm{kg}$ ) was determined in samples from both countries; however, the values did not exceed Polish standards. The higher concentration of potassium comparing to sodium and calcium was noted. The highest variation was observed for calcium; its concentration strongly depended on the country of origin.

\section{REFERENCES}

1. Afkhami A., Madrakian T., Siampour H.: Flame atomic absorption spectrometric determinate of trace quantities of cadmium in water samples after could point extraction in Triton X - 114 without added chelating agents., J. Hazard. Mater., B138, 2006.

2. Chen J., Teo K.C.: Determination of cadmium, copper, lead and zinc in water samples by flame atomic absorption spectrometry after cloud point extraction., Anal. Chim. Acta, 450, 2001.

3. De La Fuente M.A., Juárez M., Rapid determination of calcium, magnesium, sodium and potassium in milk by flame atomic spectrometry after microwave oven digestion., Analyst 120, 1, 1995.

4. Doroschuk V.O., et al.: Flame atomic absorption determination of manganese(II) in natural water after cloud point extraction., Talanta 64, 2004.

5. Heldur H., et al.: Anodic stripping voltammetric determination of cadmium in whole human blood., Electroanal.,16, 5, 2004.

6. Kozina S. A., Kushchevskaya N.F.: Inversion voltammetric determination of microconcentrations of Cd (II) and Zn (II) when they are jointly present in waters., J. Water Chem. and Tech., 30, 2008.

7. Krawczyk M., Jeszka - Skowron M., Matusiewicz H.: Sequential multi-element determination of iron and zinc in water samples by high-resolution continuum source graphite furnace atomic absorption spectrometry after column solid-phase extraction onto multiwalled carbon nanotubes., Microchem. J., 17, 2014.

8. Shah K.V., Kapupara P.K., Desai T.R.: Determination of sodium, potassium, calcium and lithium in Wheat Grass by flame photometry. J. Pharm. Sci., 2, 3, 2011.

9. Shemirani F., Abkenar S.D., Jamali M.R.: Determination of cadmium(II), copper(II) and zinc(II) in water samples by flame atomic absorption spectrometry after cloud point extraction., Indian J. Chem., Sect. A 44, 2005.

10. Sowa I., et al.: Biofortification of Soy (Glycine max (L.) Merr.) with Strontium Ions., J. Agric. Food. Chem., 62, 23, 2014 